\title{
O FEITIÇO DO TEMPO DA COMÉDIA
}

\author{
Nuno Amaral Jerónimo \& José Carlos Alexandre
}

\begin{abstract}
RESUMO
Neste artigo procura-se refletir sobre o tempo social interrompido pelo humor, como fórmula discursiva, e pela comédia, como recurso performativo. A incongruência das significações produzidas por esta forma estilística significa uma suspensão das regras de tipificação nas interações quotidianas do mundo-da-vida. Estes momentos de suspensão são designados por interrupções (time out). Neste texto mostramos como a relação do humor e da comédia com o tempo comum e com as interrupções revelam chaves interpretativas do tecido social intersubjetivo.
\end{abstract}

\section{COMEDY'S TIME SPELL}

\begin{abstract}
In this paper, the authors intend to reflect upon the social time interrupted by humor, as a discourse recipe, and by comedy, as a performative resource. The incongruity of the significations produced by this stylistic form means a suspension of the tipification rules in the life-world daily interactions. These moments of suspension are designated by time out. In this text, the authors show how humour and comedy connect with common time and time out to reveal interpretation keys to disclose the intersubjective social fabric.
\end{abstract}

KeYwORDS

Comedy; interruption; intersubjectivty; humour

\section{INTRODUÇÃo}

A proposta deste artigo é discutir como os discursos humorísticos, em particular o exercício performativo da comédia, apresentam características singulares em relação à temporalidade. Para esse propósito, acede-se a dois níveis de análise. Primeiro, as excepcionalidades no tempo social rotinado, a partir do conceito de interrupção de Stanford M. Lyman e Marvin B. Scott (1989). Segundo, os tempos específicos da performance cómica. Para recorrer a esse quadro analítico, importa antes contextualizar o humor e a comédia no campo do conhecimento das Ciências Sociais, pelos percursos teóricos do interacionismo, desde a fenomenologia de Schutz à sociologia do absurdo de Lyman e Scott.

As Ciências Sociais têm revelado que qualquer assunto, por mais superficial que possa parecer, acaba muitas vezes por revelar fenómenos complexos e intrincados. A 
elas pode caber o papel de desconstruir e desambiguar significados com o objetivo de posicionar o discurso humorístico numa base mais alargada de significação social e de entretecer a performance da comédia com as representações sociais do quotidiano.

É neste sentido que se procura encontrar o tempo próprio da formulação cómica no interior das dinâmicas fenomenológicas do humor dentro das sociedades que o produzem. A necessidade de descodificar os significados dos discursos dos agentes na sua vida quotidiana levou a Sociologia a preocupar-se com análises de pormenor.

Alfred Schutz (1967) reclamou a necessidade de reabilitar o mundo da vida quotidiana para dentro da Sociologia. Foi esta vontade de descobrir mais sobre as minudências da vida comum de todos os dias que trouxe mais autores para uma Sociologia do Quotidiano, questionando a concentração do pensamento sociológico nos grandes problemas estruturais da Humanidade ou uma hipertrofia analítica dedicada às desigualdades e aos problemas sociais, e reclamando a aproximação ao real através de um "naturalismo rebelde" (Machado Pais, 2015, p. 28) e de uma "sociologia do mundano" (Brekhus, 2000, p. 89). Segundo esta linha de reflexão que busca a notoriedade sociológica das pequenas coisas, como conversas ou ações, procura-se uma ciência do social muito mais próxima da vivência quotidiana, das ações que executamos diariamente sem que delas demos conta.

As exibições de riso e manifestações de humor são umas dessas formas de minudências comunicacionais do quotidiano, que surgem - mesmo que involuntariamente - na interação entre indivíduos. O riso, o humor e a comédia são social e culturalmente partilhados nos processos de interação social e, muitas vezes, moldadas e localizadas dentro de fronteiras espaciais e temporais.

Pode mesmo entender-se que a própria produção de discursos humorísticos, seja com intenções artísticas e performativas, seja na informalidade das interações quotidianas, se aproxima de uma microssociologia do banal (Jerónimo, 2015; Watson, 2015;). Foi também um caminho similar que os proponentes de uma sociologia do absurdo percorreram, em busca de um discernimento sobre a forma como os indivíduos conferem e constituem referências na sua vida quotidiana dentro de um mundo ontologicamente sem sentido (Jacobsen, 2009; Lyman \& Scott, 1989). A sociologia do absurdo seria, assim, uma fenomenologia existencialista do quotidiano que visa encontrar as construções culturais de sentido nas interações do mundo-da-vida (Schutz, 2003) onde, na essência da realidade, tal sentido não existe (Jacobson, 2009).

\section{INTERSUBJETIVIDADES}

Schutz $(1967,2003)$ propõe o conceito de intersubjetividade definindo-a como a forma pela qual um sujeito tem acesso experiencial a outro sujeito e se constitui uma comunidade de sujeitos na intersecção desses acessos experienciais. O mundo intersubjetivo será, dessa forma, criado e mantido pelo conhecimento de senso comum que sustenta as ações dos atores, uma vez que a "textura de sentido tem origem nas ações humanas e foi instituída por elas, pelas nossas e as dos nossos semelhantes, 
contemporâneos e antecessores" (Schutz, 2003, p. 37). Como afirmam Søren Overgaard e Dan Zahavi (2009) ou Jonathan H. Turner (2013), a intersubjetividade deve ocupar um lugar de centralidade na teoria sociológica, por se configurar como a realidade social visível mais importante num grupo. Como instrumento conceptual e analítico, a intersubjetividade pode servir para explicar como experiências múltiplas e diversas conseguem produzir e organizar estruturas de significado que criam a realidade social. A compreensão dos significados foca a sua lente nas experiências pessoais, na partilha das experiências dos outros, na aprendizagem de significados pré-atribuídos, e na iniciação em novos comportamentos significativos (Overgaard \& Zahavi, 2009).

A teoria fenomenológica mostra que a forma de viver conscientemente as experiências do mundo-da-vida se realiza através de processos de tipificação (Schutz, 2003), que desempenham um papel crucial na vida social. As tipificações são processos contínuos de organização da realidade que ajudam os indivíduos a compreender o mundo social, permitindo-lhes viver e experimentar a interação com os outros e com o meio. Estes processos de tipificação não acontecem apenas com seres vivos e objetos, mas também com situações, ações, motivos, pensamentos. Além disso, as tipificações não acontecem apenas com pessoas, objetos ou formas sociais que se conhecem pessoal ou virtualmente, mas também com aqueles com que os indivíduos nunca se tenham cruzado ou conhecido (Mann, 2008; Schutz, 2003).

Schutz (2003) sugere que todos os indivíduos estão envolvidos em ambientes sociais de significação intersubjetiva que se encontram organizados em referenciais espaciais e temporais. Os indivíduos experimentam, dessa forma, o mundo como um lugar que contém um conjunto de zonas de significação distintas e independentes. Por exemplo, os jogos das crianças, as experiências religiosas, as performances humorísticas apresentam lógicas espácio-temporais únicas.

A sensação de garantia e naturalidade fornecida por essas estruturas, devidamente arrumadas numa ordem social preexistente, exige um elemento importante aos padrões de tipificação, a pressuposição de que os outros indivíduos possuem sistemas de compreensão que se assemelham aos seus (Schutz, 2003).

Pode propor-se que, quando um comediante sobe ao palco numa noite dedicada à stand-up comed $\gamma^{\prime}$, o espetáculo decorre a partir de um processo de tipificação que permite ao espectador saber que, naquele contexto espácio-temporal, o discurso será humorístico e versará sobre temas com que o público esteja familiarizado. O público dirigiu-se a um local e hora específicos porque sabia que ali estaria alguém que o faria rir, e é isso que espera. Não será por acaso que a primeira linha do manual de escrita para comédia de John Byrne (2002, p. 1), Writing comedy, é "vá lá - faz-nos rir".

Anton C. Zijderveld (1983) entende que o humor deve ser considerado como um jogo de significados entre os vários aspetos da vida. A oportunidade cognitiva e social que os seres humanos possuem de jogar e brincar com as construções dos sentidos dos seus contextos culturais no decurso das suas ações e interações da vida quotidiana

' Os espetáculos de comédia em palco são conhecidos pela expressão inglesa stand-up comedy, e será esta a utilizada aqui, na sua formulação inglesa, uma vez que não se conhece uma expressão em português que mais bem a designe. 
permite-lhes gerir formas de experimentação e negociação de forma partilhada. De uma forma complementar, é este jogo que faz também com que os indivíduos estejam conscientes de como a vida social é algo construído e nada se encontra naturalmente atribuído (Kuipers 2008).

\section{HUMORES}

Sem propósitos de adiantar uma definição definitiva de humor, até porque tal tarefa levaria a caminhos sem retorno e sem saída, podem considerar-se humorísticos quaisquer eventos ou formulações discursivas, intencionadas ou inadvertidas, que provoquem experiências cognitivas culturalmente partilhadas capazes de suscitar o riso e providenciar divertimento.

Antes de prosseguir com uma proposta de conceptualização do humor, cabe fazer uma distinção entre humor e riso. Este é uma manifestação biológica visível, embora com contornos cognitivos e sociais invisíveis (Carroll, 2014; Critchley, 2002). Como proposição complementar, John Morreall (2012) distingue o sinal (riso) do jogo (humor).

Embora tenha havido uma profusão de propostas de definição do conceito de humor, não existe uma definição única que pudesse ser aceite em concordância por todas as disciplinas e por todos os estudiosos e investigadores. Alguns julgam mesmo ser impossível definir o humor (Cohen, 2013; Walker, 1998).

O humor apresenta-se em categorias muito diversificadas de formas e estilos. A ironia, a piada espirituosa, o humor físico (preparado ou acidental), o ridículo ou a paródia são alguns dos exemplos de formas humorísticas. Estas compreendem uma variedade de mecanismos linguísticos e retóricos, assim como físicos, usados para comunicar, socializar e interagir (Carroll, 2014). Para serem consideradas humorísticas, as mensagens devem ser mutuamente compreensíveis e suscetíveis de provocar o riso tanto para o falante como para o ouvinte - ou para o escritor e para o leitor.

O humor é uma chave para fendas sociais impregnada de discurso intersubjetivo. De forma simbólica, o humor transporta mensagens sobre expectativas sociais, interações e interpretações. As locuções humorísticas e a sua recetividade são bons indicadores dos significados culturais, das representações sociais e até do contexto histórico-político de uma comunidade (Jerónimo, 2015; Morreall, 2009). "Sem congruência social, não há incongruência cómica" (Critchley, 2002, p. 4).

\section{ComÉdias}

Por contraposição a uma conceção generalizadora de humor, a comédia é definida como "uma peça (ou outra composição literária) escrita principalmente para divertir a audiência apelando a um sentido de superioridade sobre as personagens representadas" (Baldick, 2008, p. 62). Andrew Stott (2005), Eric Weitz (2009) e Matthew Bevis (2013) corroboram esta distinção fundamental entre humor e comédia.

A comédia é essencialmente uma performance cultural que identificamos com as formas da cultura erudita e da indústria cultural. Na televisão, no cinema, na literatura 
ou no teatro, a comédia é o discurso humorístico transfigurado em produto performativo artístico.

Ao longo da História, todas as partes da vida humana têm sido objeto do olhar cómico numa tentativa de ilustrar as situações em que as pessoas se costumam encontrar no quotidiano. Mas se na cultura do Ocidente a comédia tem as suas origens na cultura greco-romana, não se pode olvidar que por todo o mundo existiram formas recorrentes de interlúdios humorísticos, tais como os papéis desempenhados pelos bobos, pelos palhaços e, mais recentemente, pelos humoristas (Minois, 2007; Otto, 2001; Southworth, 1998).

Como referência para uma autonomização conceptual, pode sugerir-se que "o humor descreve um olhar ou uma mundivisão, particular ou colectiva, e a comédia descreve uma experiência e um ambiente" (Jerónimo, 2015, p. 71).

\section{Folias}

Antes de abordar o fenómeno da comédia contemporânea, e em particular da stand-up comedy, atente-se nas abordagens clássicas de Mikhail Bakhtin (1984) e Roberto DaMatta (1997) sobre a paródia e a folia. As festas populares continham momentos de riso e humor como reações e perceções discursivas alternativas, coexistentes com os processos de interpretação habituais da realidade quotidiana.

O Carnaval pode funcionar como uma alternativa de resistência e da esfera da liberdade. Bakhtin (1984) considera as festas carnavalescas como comédias comunitárias, livres e igualitárias. DaMatta (1997) procura uma dramaturgia da singularidade brasileira num ritual de tal forma universalizado que transforma a individualidade em anonimato. Habermas (1992) reconhece que o Carnaval se pode apresentar como uma alternativa à esfera pública burguesa. Estas formas ritualizadas de convocar o humor e a paródia permitem uma forma diferente, mais popular, de participação cívica.

Bakhtin (1984), corroborado por José Mattoso (2012), descreve as sociedades medievais assentes na coexistência de duas ideologias, a diversão e a seriedade - que corresponderiam às "duas atitudes cardeais da vida - o jogo e a seriedade" (Huizinga, 2003, p. 22). Uma ideologia oficial, marcada pela escolástica e pelo Cristianismo, profundamente circunspecta, e uma outra, não oficial e subversiva, com elementos populares que contrariavam, através do humor, os desígnios da cultura oficial. O mundo quotidiano popular apresentava-se como uma espécie de segundo mundo, com peculiaridades dentro da ordem oficial medieval, e regido por formas particulares de relacionamento:

oficialmente, os palácios, igrejas, instituições e casas privadas eram dominadas pela hierarquia e etiqueta, mas no mercado era usado um tipo especial de linguagem, quase um linguajar autónomo, muito distinto da linguagem da Igreja, do palácio, das cortes e instituições. (Bakhtin, 1984, p. 154) 


\section{INTERRUPÇÕES - $1^{\mathrm{A}}$ PARTE}

A ideia de contextualização e mundivisão na produção de um sentido enviesado ou diferenciado dos discursos correntes sobre a realidade é exposta por Michael Mulkay (1998) naquilo que designa por modo humorístico. Nestas proposições, os repertórios de conhecimentos adquiridos, sejam as leis da ciência ou as crenças do senso comum, sejam a lógica ou o sentido de propriedade são suspensas durante o período que se encontra contextualmente estipulado para a duração da comédia ou da paródia. "Quando os recetores são confrontados com uma piada, eles não aplicam os procedimentos de processamento de informação apropriados ao discurso sério" (Mulkay, 1988, p. 37). Isto é, presume-se que o indivíduo que profere o discurso o faz dentro dos padrões do que confortavelmente os ouvintes (ou leitores) sabem ser um discurso cómico, que passa por ser distinto dos significados que se têm por adquiridos e verdadeiros. $O$ autor acrescenta ainda que desta forma os indivíduos têm a possibilidade de estabelecer processos interpretativos e comunicativos em relação às experiências incongruentes que surgem todos os dias na vida quotidiana.

O humor pode ser empregue para expor e expressar os aspetos contraditórios da vida ou pode ser usado em simultâneo para partilha de experiências com outros grupos ou indivíduos. O humor, precisamente por ficar circunscrito a um círculo de significações próprios, dificilmente destituirá a ordem estabelecida. Peter Berger (1999) explica que esta é a razão pela qual o humor necessita de fronteiras bem definidas para não extravasar nem provocar ansiedade em vez de divertimento. Pelo contrário, acaba por servir para manter o equilíbrio social bem como para consolidar a ordem. Por exemplo, com uma piada sexual, o humor sexista pode estar relacionado com as normas contraditórias e com as expectativas que orientam as relações sociais de género (Bore, 2010; Kuipers, 2008).

Como foi referido, a perspetiva fenomenológica considera que existe um contraste entre as abordagens humorísticas à realidade e as interpretações sérias. Berger (1999) considera que o humor tem uma atitude intrusiva na realidade, tal como tem a religião. Para este autor, humor e religião representam parcelas finitas da realidade, que produzem mundos de significações separadas do mundo da vida comum e que operam com regras diferentes desta. A experiência vivida numa situação ou formulação cómica promete uma forma de redenção através do riso. A teoria para uma compreensão do humor proposta por Berger parte da perspetiva construtivista, mas, por outro lado, aproxima-se da teoria psicológica do alívio através de uma volta teológica (Kuipers, 2008). Embora a conceção de Berger (1999) tenha ressonâncias com o humor curativo, a sua confiança nos aspetos redentores do humor e do riso criam uma visão particularmente unívoca do humor.

A abordagem construtivista à interpretação do humor determina essencialmente que a realidade do contexto humorístico corresponde a um contrato flexível entre o contador de anedotas e a sua audiência. A interpretação do humor é vista como uma forma de contrato social ou uma forma de cooperação na conversa que ocorre entre as duas partes. Dito de outra forma, uma piada negociada é uma piada construída. A interação ganha prioridade neste tipo de análise e o foco da investigação move-se do conteúdo 
da anedota para o contexto da interação. Não é possível forçar o sentido de humor, este deve emergir dos processos de interiorização e exteriorização. As normas de conduta social como ouvir sem interromper ou sorrir no fim podem fazer parte deste contrato social - e os processos de construção social das normas estão fortemente ligados a significações tipificadas do tempo com amplitudes e diferenças significativas em contextos culturais diferenciados (Hall, 1959). A interação humorística é, pela sua natureza, uma interação em que as regras normais da lógica se encontram suspensas, como são também muitas das normas sobre convenções sociais e tabus:

cómicos e satíricos esticam os limites dos comentários sobre religião, raça, capitalismo, identidade de género, orientação sexual, o sistema político, estereótipos e uma miríade de outros tópicos que os pais tipicamente ensinam os seus filhos a não discutir com companhias educadas. (Landreville, 2012, s.p.)

A contratualização social sobre o discurso humorístico requer que todos os participantes numa interação com base humorística compreendam as convenções que são próprias do humor específico de cada grupo, para que a inteligibilidade não se transforme em ruído. Este é um aspeto do humor que pode contribuir para a coesão interna do grupo. Reconhecer simplesmente a distinção entre a conversa corrente e o início de um discurso humorístico requer um conhecimento íntimo da cultura. Por estas razões, a tradução do humor de uma cultura para outra pode estar dificultada e estará muitas vezes condenada ao fracasso.

\section{INTERRUPÇÕES - $2^{\mathrm{A}}$ PARTE}

Sem desprezo pelas discussões físicas (Rovelli, 2018), ontológicas (Baker, 2010), históricas (Holford-Strevens, 2008) ou literárias (Borges, 2011) sobre o tempo, neste artigo pretende-se considerar a noção intersubjectiva de tempos sociais, de momentos partilhados por um grupo social como tendo características estruturantes genericamente similares que, de algum modo, configuram "o ritmo da vida social que está na base da categoria do tempo" (Durkheim, 1996, p. 489).

Para este efeito, considera-se uma formulação das linhas de tempo, apresentada por Lyman e Scott (1989) na sua teorização sociológico-existencialista para uma sociologia do absurdo. Para estes autores, a perceção das linhas temporais é inteiramente subjetiva, e os indivíduos podem sentir-se numa linha de tempo fatalista, ou numa linha de tempo humanista. Esta reflexão centra-se essencialmente na proposta teórica de Lyman e Scott (1989) sobre tempos laterais, alternativos e paralelos ao tempo comum, aqueles que se constituem como variações e interrupções da continuidade temporal. É um enquadramento da comédia nesses tempos fora do tempo que se questiona. Não se procuram analisar os tempos internos da performance artística, mas decifrar o contexto em que a comédia dobra as convenções e cria um conjunto de significações com autonomia discursiva. 
Pode dizer-se que Lyman e Scott (1989) apresentam três linhas paralelas ao tempo corrente da vida quotidiana: a espera, a interrupção e o abandono. Destas três linhas, interessa focar particularmente a segunda. O humor é uma interrupção.

Os autores definem o período de interrupção (time out, no original) como "a pausa de atividades relacionadas com uma linha temporal específica, um período onde as regras e os papéis relacionados com essa linha são relaxados ou revogados. No decurso deste estado específico, comportamentos contraditórios ou irrelevantes serão considerados impunes" (Lyman \& Scott, 1989, p. 44).

A interrupção pode também servir para distinguir oposições discursivas, como "o sisudo do jocoso, o sagrado do profano, o impessoal do íntimo" (Lyman \& Scott, 1989, p. 45).

Analogamente, o período de interrupção (time out) do trabalho no mundo moderno, institucionalizado nas organizações, é o coffee-break; e, nos desportos coletivos, os períodos de tempo em que o jogo está interrompido para as equipas técnicas darem novas instruções aos jogadores. De uma forma similar, o humor é um intervalo do jogo do quotidiano, um processo de interação em que os indivíduos reconstroem as formas sociais (Simmel, 1910) e recebem novas instruções de codificação e descodificação da realidade (Durkheim, 1996). Em situações de encenação performativa, essas instruções são os contextos em que se desenrolam as piadas proferidas pelos comediantes.

Se o humor for entendido como processo intersubjetivo que compõe um quotidiano desnaturalizado, tecido a partir das tipificações do mundo-da-vida, pode concluir-se que a discursividade humorística exibe o ridículo e evidencia a relatividade das construções sociais, da vida quotidiana e das estruturas culturais:

o humor transforma-se num espelho levantado na face dos indivíduos que Ihes possibilita olharem para o mundo e mesmo para eles próprios de uma qualquer forma aparentemente distorcida em relação às tipificações conhecidas. O humor revela o caminho da construção social daquilo que parece aparentemente real, mas é apenas realmente aparente. (Jerónimo, 2015, p. 26)

O humor, como fórmula discursiva de interação quotidiana, pode encontrar-se nos mesmos caminhos da conversação banal entre indivíduos, mas a comédia, com a sua execução performativa, assume mais claramente o seu papel de interrupção às linhas do tempo com que as vidas humanas se entretecem.

Sem a compreensão tipificada de que a comédia assume um formato de interrupção do tempo comum, cair-se-ia no terreno ambíguo da ironia pós-moderna. Se deixar de haver correspondências entre significados adquiridos e discursos produzidos, não haverá sentidos de verdade e mentira. Tal mundo seria profundamente irónico, porque nenhum discurso poderia ser validado, justificado ou consubstanciado (Colebrook, 2004).

\section{REPETIÇÕES}

$\mathrm{Na}$ sequência dos discursos mais pessimistas sobre a cultura (Adorno, 2003; Arendt, 1996) ou sobre o discurso público (Frankfurt, 2006; Sunstein, 2010), chegaram 
também as visões menos alegres sobre o riso no mundo contemporâneo (Billig, 2001; Lipovetsky, 1989; Minois, 2007).

A explosão de produtores e produtos humorísticos tem assolado o espaço mediático de uma forma impossível de controlar, quer do ponto de vista da intervenção sobre o significado, quer na dimensão de espectador, impossibilitado de acompanhar e conhecer tudo o que é produzido sob a forma de comédia em todos os meios e plataformas que a tecnologia hoje possibilita. Esta detonação do humor, indistinta para os espaços público e privado, extravasou para todos os momentos e dimensões da vida quotidiana e invadiu as estruturas sociais mais perenes. O impulso invasor do fenómeno humorístico incorpora já todas as esferas da vida social (Lipovetsky, 1989).

Uma sociedade humorística não pretende dessacralizar, já nada há a dessacralizar. A trivialização do riso promove que este se consuma em vazio, num mundo plano, unidimensional, onde tudo deve ser transmitido com leveza e boa disposição, sem preocupações éticas sobre o seu conteúdo, naquilo a que Frankfurt (2006) designa por "conversa da treta".

Se as dimensões institucionais da vida (o Estado, a religião, a política, o trabalho) deixaram de ter um carácter de seriedade e foram perpassadas pela força das vagas do humor, a comicidade do contraste desaparece (Minois, 2007). Desta forma, o humor torna-se um cliché vagamente irónico ou mesmo um pouco sarcástico, quando não simplesmente cínico (Hernández Sánchez, 2012) mas claramente irreflexivo.

O humor em permanência total deixa de ser um método capaz de estilhaçar as ideias convencionais e acaba por se converter ele próprio em apenas mais uma das convenções que anteriormente desconstruía. O que sobra são esgares automatizados, sorrisos ritualizados por piadas convencionadas. O humor torna-se iterativo e expectável (Eco, 1991). "O riso autêntico é gradualmente retirado da festa, vem substituí-lo a máscara do riso, rígida, artificial e obrigatória" (Minois, 2007, p. 641).

\section{CÂNONES}

A inteligibilidade do discurso humorístico compreende, portanto, também as suas referências temporais (e atemporais). A comédia, ao canalizar as referências para características do anti-herói ridicularizável, não se preocupa com a historicidade do seu discurso, tornando essas referências muitas vezes circunscritas ao público seu contemporâneo.

De acordo com a formulação proposta por David Lowenthal (2015) de que o passado é um país estrangeiro, as distâncias temporais têm no discurso humorístico e cómico o mesmo efeito de afastamentos culturais. Ao contrário das tragédias clássicas, que continuam a provocar emoções séculos após a sua escrita, a Velha Comédia grega de Aristófanes dificilmente arrancará ao público do século XXI risos iguais aos que proporcionava nos festivais dionisíacos do século $\vee$ a.C. (McGowan, 2017).

A relação imediata do público com a comédia é exacerbada nas performances da stand-up comedy, o que a coloca nas fronteiras da pós-modernidade, sem consideração pelo passado nem pelo futuro (Martins, 2011). Pelas suas características de imersão 
total numa esfera presentista que combina o momento histórico, o lugar geográfico e o contexto cultural, a comédia não perspetiva o futuro nem reflete sobre o passado.

Mesmo tendo destinatários do momento presente em que o discurso humorístico é proferido, tal não significa que a historicidade narrativa seja elemento da facécia. Habitualmente, a performance cómica não estabelece ordens cronológicas - a não ser que a preparação da piada necessite - nem organiza a informação na habitual organização telescópica da temporalidade.

O humor compromete-se com os absurdos e os ridículos de cada tempo e lugar que surgem apontados pelo olhar do comediante. Perante a tragédia da vida, diz Michel Maffesoli que esta atitude perante o presente serve para "canonizar o que existe" (citado em Martins, 2011, p. 123), sem propor alternativas nem superações. O discurso humorístico, enredado numa a-historicidade fluida, supera a realidade sem sair do presente. Ou mais acertadamente, sem estar na linha do tempo. O presentismo das sociedades contemporâneas, como advertem Gilles Lipovetsky (1989), Michael Billig (2001) ou Roger Minois (2007), poderá ser o melhor alimento de uma sociedade contaminada pelo riso.

\section{LEVANTADOS}

Muitas verdades são ditas a brincar e muitas mentiras em tom sério. "Um homem pode dizer toda a verdade no jogo e na diversão", escreveu Geoffrey Chaucer (2003) no "Prólogo do cozinheiro", no seus Contos da Cantuária do século XIV. Aqueles que usam a linguagem cómica, como bobos, palhaços, jograis e menestréis, ou seus equivalentes históricos, bem como os humoristas profissionais contemporâneos, são habitualmente personagens muito populares através dos tempos e culturas (Apte, 1985; Minois, 2007; Sanders, 1995).

Como afirmou o cómico norte-americano Robin Williams, "stand-up é onde podes fazer coisas que nunca poderias fazer em público. Quando pisas o palco estás autorizado a fazê-lo" ${ }^{2}$. Autores experimentados na produção de comédia, como John Byrne (2002) Peter McGraw e Joel Warner (2014), ou Oliver Double (2014), consideram o palco como o lugar primevo do comediante, situado em frente ao público.

Nos Estados Unidos, a tradição da stand-up comedy desenvolveu-se durante o século XX a partir das tradições americanas do burlesco e do vaudeville, incluindo o humor físico, as imitações e a ridicularização (Todarello, 2006). A stand-up comedy cresceu em escala e sofisticação a partir do fim da Segunda Guerra Mundial e tornou-se, na produção humorística americana, uma forma muito popular de entretenimento, chegando à rádio e à televisão, suportando um circuito próprio de clubes noturnos e atingindo, mais recentemente, a rede (Lewis, 2006; McGraw \& Warner, 2014; Sanders, 1995).

A stand-up comedy pode ser caracterizada por três indicadores: personalização; comunicação direta; tempo presente. A personalização respeita à presença do comediante em frente à audiência, seja uma caricatura, seja uma versão do self do comediante. A

${ }^{2}$ Frase atribuída a Robin Williams em várias coletânea de citações, sem nunca referir o tempo ou o local em que foi proferida. 
comunicação direta refere-se à relação estabelecida entre o comediante e o público presente na sala. O tempo presente é a coordenação do comediante com o momento em que a performance é realizada (Double, 2014, pp. 19-20).

A stand-up comedy, pelas suas características únicas de autoria e performance, afasta-se das linhas de tempo humanistas e fatalistas, e aparece de forma muita nítida como um espaço privilegiado onde todos os intervenientes estão conscientes com a interrupção das linhas temporais do quotidiano.

\section{ECRÃS}

Os comediantes profissionais ocupam na contemporaneidade um lugar importante na arena mediática e posicionam-se no campo cultural como figuras relevantes na interpretação dos discursos sociais³.

A "cultura do ecrã" manifesta-se na sua horizontalidade, uma cultura de todos para todos (Lipovetsky \& Serroy, 2010). No mesmo ecrã para onde olhamos está a câmara que nos fita. Hoje, a profusão de conteúdos humorísticos de acesso imediato, como a Porta dos Fundos no YouTube ou os especiais de stand-up comedy na Netflix, permite a sua visualização em qualquer aparelho móvel conectado à rede digital. Como acrescentam Gilles Lipovetsky e Jean Serroy (2010), os consumos culturais no segundo ato do ecrã global passaram a ser absolutamente individualizados e personalizados. Essa individualização passa também pela mediação entre tempo e tecnologia, e o uso particularizado de conteúdos em rede:

vídeos produzidos em esferas fora da rede podem ser trocados e partilhados apenas se forem colocados em novos contextos (por exemplo, sítios da rede), sendo assim distanciados do contexto original e trocados por pessoas que vivem em diferentes fusos horários e experimentam tempos diferentes na sua calendarização quotidiana. (Tsatsou, 2009, p. 14)

Uma curiosidade que denota o poder da habituação do público aos termos da comédia, nos termos da perceção intersubjetiva das regras da comédia, diz respeito ao tempo de duração das performances cómicas: "duração é a assunção mais amplamente difundida no que respeita à natureza do tempo no mundo ocidental. Para quem aprendeu a lidar e a dar o tempo por garantido parece inconcebível que se possa viver de outra maneira" (Hall, 1959, p. 171).

Os especiais produzidos pela Netflix surgem em três modelos distintos, mas que respeitam a prática originária dos cafés e teatros - séries de comediantes de 15 e 30 minutos e especiais autónomos de aproximadamente 60 minutos.

Numa plataforma de streaming individualizado, poderia pensar-se que a duração de um espetáculo não sofreria dos mesmos constrangimentos das transmissões clássicas da televisão, onde uma grelha horária impõe durações cronometradas ao segundo.

\footnotetext{
3 Esta posição nos campos sociais e culturais não foi sempre considerada benéfica. Platão, por exemplo, defendia que "devemos deixar tais representações para os escravos ou estrangeiros contratados, que nenhuma atenção séria lhes seja prestada e que nenhum homem ou mulher livres sejam vistos a tirar daí algum ensinamento" (Leis: VII-816).
} 
É apenas nessa margem de alguns minutos que se pode notar um pequeno reflexo da liberdade das plataformas de difusão individual em relação à grelha de programação, ao apresentarem espetáculos de comédia (e episódios de séries) de 60 e poucos minutos.

Nos espetáculos colocados em linha pela Netflix no ano de 2018 , todos têm uma duração que ronda uma hora. Não sendo por motivos de constrangimento técnico ou de programação, será ainda uma estipulação cultural por habituação ainda muito próxima dos espetáculos ao vivo e das transmissões televisivas clássicas.

O canal Porta do fundos no YouTube parece ser um exemplo de alguma liberdade em relação ao tempo cómico, mas apenas por não sofrerem do constrangimento de terem de coligir os sketches num programa de duração maior. A duração irregular dos sketches, por serem colocados na plataforma individualmente, não exige nenhum esforço de montagem para obter um programa de 25 ou 45 minutos. Veja-se a diferença, do ponto de vista técnico, com o programa da BBC iniciado em 1969, Monty Python flying circus, onde os autores, para ligarem os sketches e obterem a duração estipulada pela estação britânica para cada episódio, se viram na necessidade de introduzir os desenhos pós-surrealistas de Terry Gilliam.

\section{ConClusÃo: PUNCHLINES}

E se fôssemos rir, / Rir de tudo, tanto / Que à força de rir / Nos tornássemos pranto? Alexandre O'Neill

A reflexão contida neste artigo procura enquadrar o humor como uma fórmula discursiva da interação quotidiana e um processo intersubjetivo de produção de significados que subvertem a ordem habitual do mundo-da-vida, mas devidamente organizados pelos processos de tipificação decorrentes das práticas sociais que envolvem formulações humorísticas.

O humor é entendido, nos espaços de sociabilidade, como uma intervenção comunicacional alternativa. O humor ocupa um tempo com regras estilísticas e pragmáticas próprias, reconhecidas pelos indivíduos envolvidos. O humor é uma interrupção ao tempo comum, e a comédia, com as suas formas performativas reconhecidas ao longo da história das artes e do espetáculo, assume de maneira evidente essa condição de interrupção do tempo comum.

A comédia, sendo uma interrupção subversiva, corre o risco de se tornar repetitiva e colonizadora do espaço público, e com isso criar um espaço permanente de interrupção, fruto de um humor artificializado e aprisionado na sua iteração.

Um espaço permanente de interrupção não permite o regresso ao tempo comum, que se tornaria, por sua vez, a verdadeira discursividade alternativa e subversiva.

O risco de um espaço público em estado de interrupção e facécia permanente é o de um espaço público centrando na atemporalidade e na canonização do presente promovida pelas propriedades típicas da discursividade humorística. Seria uma sociedade sem tempo para a reflexão histórica. 
As tecnologias promoveram uma individualização das práticas de consumo da comédia, embora não tenham afastado as audiências da sua relação direta com as performances. No entanto, apesar das alterações que a individualização produziu, a comédia não perdeu ainda os formatos temporais a que o público se foi habituando desde a Velha Comédia dos festivais de Lenaia.

\section{REFERÊNCIAS}

Adorno, T. W. (2003). Sobre a indústria da cultura. Coimbra: Angelus Novus.

Apte, M. (1985). Humor and laughter: an anthropological approach. Ithaca, Nova lorque: Cornell University Press.

Arendt, H. (1996). La crisis en la cultura: su significado político y social. In H. Arendt, Entre el pasado y el futuro - Ocho ejercicios sobre la reflexión política (pp. 303-346) Barcelona: Ed. Península.

Baker, L. R. (2010). Temporal reality. In J. K. Campbell, M. O'Rourke \& H. S. Silverstein (Eds.), Time and identity (pp. 27-47). Cambridge, MA: The MIT Press.

Bakhtin, M. M. (1984). Rabelais and his world. Bloomington: Indiana University Press.

Baldick, C. (2008). Oxford dictionary of literary terms. Oxford: Oxford University Press.

Berger, P. (1999). Risa redentora. Barcelona: Kairós.

Bevis, M. (2013). Comedy - a very short introduction. Oxford: Oxford University Press.

Billig, M. (2005). Laughter and ridicule - towards a social critique of humour. Londres: Sage

Bore, I. K. (2010). (Un)funny women: TV comedy audiences and the gendering of humour. European Journal of Cultural Studies, 13(2), 139-154.

Borges, J. L. (2011). El tiempo. In J. L. Borges, Miscelánea (pp. 243-253). Barcelona: Penguin Random House.

Brekhus, W. (2000). A mundane manifesto. Journal of Mundane Behavior, 1(1), 89-106.

Byrne, J. (2002). Writing comedy. Londres: Bloomsbury Methuen Drama.

Chaucer, G. (2003). The canterbury tales. Londres: Penguin.

Cohen, T. (2013). Humor. In B. Gaut \& D. Mclver Lopes, D. (Eds.), The Routledge companion to aesthetics (pp. 425-430). Londres: Routledge.

Colebrook, C. (2004). Irony. Londres: Routledge.

Critchley, S. (2002). On humour. Londres: Routledge.

DaMatta, R. (1997). Carnavais, malandros e heróis - para uma Sociologia do dilema brasileiro. Rio de Janeiro: Rocco.

Double, O. (2014). Getting the joke: the inner workings of stand-up comedy. Londres: Bloomsbury.

Durkheim, É. (1996). As Formas elementares da vida religiosa. São Paulo: Martins Fontes.

Eco, U. (1991). Apocalípticos e integrados. Lisboa: Difel. 
Frankfurt, H. G. (2006). Da treta. Viana do Castelo: Livros de Areia.

Góes, P. (2009). O problema do riso em O nome da rosa, de Umberto Eco. Aurora, 21(28), 213-240

Habermas, J. (1992). Further reflections on the public sphere. In C. Calhoun (Ed), Habermas and the public sphere (pp. 421-461). Cambridge, MA: The MIT Press.

Hall, E. T. (1959). The silent language. Garden City, Nova Iorque: Doubleday \& Co.

Hernández Sánchez, D. (2012). A comédia do sublime. Lisboa: Nova Vega.

Holford-Strevens, L. (2008). Pequena história do tempo. Lisboa: Tinta da China.

Huizinga, J. (2003). Homo Ludens - um estudo sobre o elemento lúdico da cultura. Lisboa: Ed. 70.

Jacobsen, M. H. (2009). The sociology of the absurd: an absurd man in an absurd world. In M. H. Jacobsen (Ed.), Encountering the everyday - an introduction to the sociologies of the unnoticed (pp. 279-303). Nova lorque, NY: Palgrave MacMillan.

Jerónimo, N. A. (2015). Humor na sociedade contemporânea. Tese de Doutoramento, Universidade da Beira Interior, Covilhã, Portugal Retirado de https://ubibliorum.ubi.pt/bitstream/10400.6/3974/1/TD_Nuno_ Jer\%(3\%B3nimo.pdf

Keightley, E. (2012). Introduction: time, media and modernity. In E. Keightley (Ed.), Time, media and modernity (pp. 1-22). Basingstoke: Palgrave MacMillan.

Kuipers, G. (2008). The sociology of humor. In V. Raskin (Ed.), The primer of humor research (pp. 365-402). Berlim/Nova Iorque: Mouton de Gruyter.

Landreville, K. (2012). Laughter and the political landscape. In The Society Pages Roundtables [website]. Retirado de http://thesocietypages.org/ roundtables/humor/

Lewis, P. (2006). Cracking up: American humor in a time of conflict. Chicago: University of Chicago Press.

Lipovetsky, G. (1989). A era do vazio - ensaios sobre o individualismo contemporâneo. Lisboa: Relógio d’Água.

Lipovetsky, G. \& Serroy, J. (2010). O ecrã global. Lisboa: Ed. 70.

Lowenthal, D. (2015). The past is a foreign country (revisited). Cambridge: Cambridge University Press.

Lyman, S. M. \& Scott, M. B. (1989). A sociology of the absurd. Nova lorque: General Hall.

Machado Pais, J. (2015). Sociologia da vida quotidiana. Lisboa: Imprensa de Ciências Sociais.

Mann, D. (2008). Understanding society - a survey of modern social theory. Ontario: Oxford University Press Canada.

Martins, M. L. (2011). Crise no castelo da cultura - das estrelas para os ecrãs. Coimbra: Grácio Editor.

Mattoso, J. (2012). Levantar o céu - os labirintos da sabedoria. Lisboa: Temas e Debates.

McGowan, T. (2017). Only a joke can save us - a theory of comedy. Evanston: Northwestern University Press.

McGraw, P. \& Warner, J. (2014). The humor code - a global search for what makes things funny. Nova lorque: Simon \& Schuster.

Minois, G. (2007). História do riso e do escárnio. Lisboa: Ed. Teorema. 
Morreall, J. (2009). Comic relief - a comprehensive philosophy of humor. Chichester, West Sussex: Wiley-Blackwell.

Mulkay, M. (1988). On humour: Its nature and its place in modern society. Cambridge: Polity Press.

Otto, B. K. (2001). Fools are everywhere - the court jester around the world. Chicago: University of Chicago Press.

Overgaard, S. \& Zahavi, D. (2009). Phenomenological sociology - the subjectivity of everyday life. In M. H. Jacobsen (Ed.), Encountering the everyday - an introduction to the sociologies of the unnoticed (pp. 93-115). Nova lorque: Palgrave MacMillan.

Platão (360 a.C.). Laws [Leis]. Retirado de http://www.perseus.tufts.edu/hopper/

Reading, A. (2012). Globital time: time in the digital globalised age. In E. Keightley (Ed.), Time, media and modernity (pp. 143-162). Basingstoke: Palgrave MacMillan.

Rovelli, C. (2018). A ordem do tempo. Carnaxide: Objectiva.

Sanders, B. (1995). Sudden glory - laughter as subversive history. Boston: Beacon Press.

Schutz, A. (1967). The phenomenology of the social world. Evanston: Northwestern University Press.

Schutz, A. (2003). El problema de la realidad social - Escritos I. Buenos Aires: Amorrortu.

Simmel, G. (1910). How is society possible. American Journal of Sociology, 16, 372-391

Southworth, J. (1998). Fools and jesters at the english court. Gloucestershire: Sutton Publishing.

Stott, A. (2005). Comedy. Londres: Routledge.

Sunstein, C. (2010). Dos rumores. Alfragide: D. Quixote.

Todarello, N. (2006). Le arti della scena. Lo spettacolo in Occidente da Eschilo al trionfo dell'opera. Novi Ligure: Latorre.

Tsatsou, P. (2009). Reconceptualising 'time' and 'space' in the era of electronic media and communications. PLATFORM: Journal of Media and Communication, 1, 11-32.

Turner, J. H. (2013). Contemporary sociological theory. Thousand Oaks, CA: Sage.

Walker, N. A. (1998). What is so funny? humor in american culture. Wilmington, DE: Scholarly Resources.

Watson, C. (2015). A sociologist walks into a bar (and other academic challenges): towards a methodology of humour. Sociology, 49(3), 407-421.

Weitz, E. (2009). The Cambridge introduction to comedy. Cambridge: Cambridge University Press.

Zijderveld, A. (1983). The sociology of humour and laughter. Current Sociology, 31(3), 1-6.

\section{NOTAS BIOGRÁFICAS}

Nuno Amaral Jerónimo é doutorado em Sociologia pela Universidade da Beira Interior desde 2015. Professor auxiliar do Departamento de Sociologia da Universidade da 
Beira Interior desde 2015. Assistente do mesmo departamento entre 1998 e 2015. Colaborador do jornal O Interior desde 2000. Foi redator da seção "Inimigo Público", entre 2004 e 2008. É coautor do livro Como ficar estupidamente culto em apenas 10 minutos, 2004. É membro da direção do projeto cultural "New Hand Lab", desde 2019.

ORCID: https://orcid.org/o0oo-0003-2452-0417

Email: nunoaj@ubi.pt

Morada: Faculdade Ciências Sociais e Humanas, Rua do Sineiro, 6200-209 CoviIhã, Portugal

José Carlos Alexandre é doutorado em Ciências da Comunicação pela Universidade da Beira Interior, desde 2017. Professor Adjunto e subdirector (2009-2015) da Escola Superior de Educação, Comunicação e Desporto do Instituto Politécnico da Guarda. É investigador no LabCom. IFP e autor de diversos artigos e do livro Uma genealogia da espiral do silêncio: a expressão da opinião sobre as praxes académicas.

ORCID: https://orcid.org/oooo-0002-8262-5279

E-mail: jcalexandre@ipg.pt

Morada: Instituto Politécnico da Guarda, Av. Francisco Sá Carneiro, 50, 6300-559, Guarda, Portugal

Submetido: 01/10/2018

Aceite: $21 / 12 / 2018$ 